\title{
The Aqueous Thermodynamics and Complexation Reactions of Anionic Silica Species to High Concentration: Effects on Neutralization of Leaked Tank Wastes and Migration of Radionuclides in the Subsurface
}

(Project Number: 70163)

\section{Principal Investigators}

Dr. Andrew R. Felmy

Pacific Northwest National Laboratory

P.O. Box 999, MSIN K8-96

Richland, WA 99352

509-376-4079 (phone)

509-376-3650 (fax)

ar.felmy@pnl.gov

Dr. Gregory Choppin

The Florida State University

Department of Chemistry, B-164

Tallahassee, FL 32606-3006

904-644-3875 (phone)

904-644-8281 (fax)

Choppin@chemmail.chem.fsu.edu

Dr. David A. Dixon

Pacific Northwest National Laboratory

P.O. Box 999, MSIN K1-83

Richland, WA 99352

509-372-4999 (phone)

509-375-6631 (fax)

da.dixon@pnl.gov 


\section{Research Objective}

Highly basic tank wastes contain several important radionuclides, including ${ }^{90} \mathrm{Sr},{ }^{99} \mathrm{Tc}$, and ${ }^{60} \mathrm{Co}$, as well as actinide elements (i.e., isotopes of $\mathrm{U}, \mathrm{Pu}$, and $\mathrm{Am}$ ). These highly basic tank wastes are known to have leaked into the vadose zone at the Hanford Site. Upon entering the sediments in the vadose zone, the highly basic solutions dissolve large concentrations of silica from the silica and aluminosilicate minerals present in the subsurface. These dissolution reactions alter the chemical composition of the leaking solutions, transforming them from a highly basic (as high as $2 \mathrm{M} \mathrm{NaOH}$ ) solution into a pore solution with a very high concentration of dissolved silica and a significantly reduced $\mathrm{pH}$. This moderately basic ( $\mathrm{pH} 9$ to 11$)$, high-silica solution has the potential to complex radionuclides and move through the subsurface. Such strong radionuclide complexation is a currently unconsidered transport vector that has the potential to expedite radionuclide transport through the vadose zone. These strong complexation effects have the ability to significantly alter current conceptual models of contaminant migration beneath leaking tanks.

In this project, we are determining the aqueous thermodynamics and speciation of dissolved silica and silica-radionuclide complexes to high silica concentration using a combination of

1. studies of chemical species structure and composition [via nuclear magnetic resonance (NMR) and, where applicable, laser-induced fluorescence spectroscopy and x-ray absorption spectroscopy]

2. molecular simulations to help identify key species structures and assist in interpreting experimental measurements

3. fundamental physical chemistry measurements, including solubility, electromotive force, and isopiestic measurements, to obtain the necessary thermodynamic data for predicting contaminant complexation and waste neutralization reactions.

The radioactive elements we are studying include $\mathrm{Sr}, \mathrm{Co}, \mathrm{Cs}, \mathrm{Am}(\mathrm{III})$, and U(VI).

\section{Research Progress and Implications}

This report covers the first 2 years of this 3-year project . Our research efforts have been focused in three principal areas: silica speciation studies, complexation studies, and reactive transport modeling. 


\section{Silica Speciation Studies}

\section{Speciation and Aqueous Thermodynamics}

In aqueous solutions containing moderate concentrations of dissolved silica (i.e., $\sim 0.01 \mathrm{M}$ ) and high $\mathrm{pH}(>10)$, a wide range of silica species can be simultaneously present in solution. These species can include monomers, dimers, trimers, tetramers, and hexamers. The final result was an accurate aqueous thermodynamic model for silica species valid to high ionic strengths and high dissolved silica concentrations

\section{Molecular Simulations}

A molecular modeling capability also was developed to help identify structural reasons for observed polysilicate stability, the tendency of the polysilicates to protonate or react with counter ions, and the stability of the polysilicate-metal complexes. Unfortunately, existing molecular modeling capabilities cannot simulate the full range of interactions including fully solvated complexes; dissociating water molecules (which allows protonation); and inclusion of counter ions (i.e., $\mathrm{Na}^{+}$). Fortunately, extensive crystallographic investigations of the structures of $\mathrm{NaOH} \cdot \mathrm{nH}_{2} \mathrm{O}$ provide valuable information on the sodium-water and hydroxide-water interaction in well-defined structures. Therefore, we began the development of our modeling capability by conducting computational investigations on the five major $\mathrm{NaOH}$ hydrates whose proton positions have been determined: $\mathrm{NaOH} \cdot(1,3.5,4 \alpha, 4 \beta, 7) \mathrm{H}_{2} \mathrm{O}$. The structural uncertainties associated with the hydrated crystals are much more controlled than in the case of aqueous species; hence, the structural analysis can proceed with less ambiguity. As a first step, we used plane wave pseudopotential density functional methods invoking the Perdew-Burke-Ernzerhof exchange-correlation functional to investigate theoretically the structures of five $\mathrm{NaOH}$ hydrates through optimization of lattice parameters and atomic coordinates. This task resulted in the final molecular model used to identify the effects of counter-ion binding and protonation of the aqueous silica complexes.

\section{Kinetics of Polymerization}

In addition to the equilibrium thermodynamics of the silicate species, the polymerization kinetics of the aqueous silicate species was studied in a companion effort at Florida State University. Information on the kinetics of polymerization is needed not only to assist in determining the expected equilibration times for the equilibrium speciation studies but also for interpreting the kinetic data for mineral dissolution reactions. In the latter case, polymerization of polysilicate species can be a rate-limiting step in silicate mineral dissolution because monomeric units are believed to control the rate of dissolution. To investigate these issues, the kinetics of the silica 
polymerization reactions was investigated by monitoring the concentration of monomeric orthosilicate using the silica molybdate absorbance method. In this way, the fraction of ortho-silicate was determined over broad ranges of total silica concentration, $\mathrm{pH}$, ionic strength, and aging time.

These studies provided detailed information on the kinetics of polymerization of ortho-silicates. In general, the silicate polymerization rate occurred on the order of minutes to hours, depending upon the specific ionic strength, $\mathrm{pH}$, and total silica concentration studied. The initial rate of polymerization was quite rapid, but a slower rate of polymerization subsequently was observed, due presumably to the formation of higher-order polysilicates. The final equilibrium data also were compared satisfactorily to the aqueous thermodynamic model for polysilicates described above.

\section{Identification of Enantomers}

In addition to these thermodynamic results, our NMR analysis also was able to identify previously unknown enantomeric forms of the polysilicate species and thereby explain many previously unidentified peaks in the NMR spectra.

To date, 16 different silicate polymers in concentrated aqueous solutions have been identified conclusively (see Figure 1), with the largest of these containing eight silicon atoms. Essentially all of the found polymers beyond the monomer and dimer were identified solely through the use of solution state ${ }^{29} \mathrm{Si}$ NMR measurements. However, despite the success of past workers in identifying the highest concentration polymers, numerous features in the ${ }^{29} \mathrm{Si}$ NMR spectra of silicate solutions cannot be explained in terms of the 16 known species. This is clearly illustrated in the ${ }^{29} \mathrm{Si} \mathrm{NMR}$ spectrum shown in Figure 2. The spectrum is a superposition of spectra from different polymers, and the complicated appearance reflects the numerous distinct molecules that must be present in the solution. Sixty-six resolved lines can be counted in this spectrum, although many more have undoubtedly been missed due to spectral overlap and/or weak signal intensity. Of the 66 lines, the 16 known polymers account for only 32.

The one-dimensional NMR techniques used in previous studies have largely been ineffective in deducing silicate structures from the remaining unassigned NMR peak information. Alternative methods that avoid these difficulties in obtaining the desired correlation information have been introduced in the time since the one-dimensional silicate work was originally reported. These alternative techniques are based on two-dimensional homonuclear correlation spectroscopy (COSY) experiments of ${ }^{29} \mathrm{Si}$-enriched silicate solutions. With the new data contained in recently acquired two-dimensional spectra, we have renewed the search for silicate polymers that have eluded previous investigators. 


Total number of
silicon atoms $N=1$

Figure 1. Silicate polymers previously found by ${ }^{29} \mathrm{Si}$ NMR spectroscopy to exist in aqueous solution. The circles represent $\mathrm{Si}$ atoms and the sticks symbolize bridging $\mathrm{O}$ atoms. The number of ${ }^{29} \mathrm{Si}$ NMR lines associated with each structure is shown next to the molecule. The hexamer in the shaded box has been identified in both cis and trans isomeric forms.

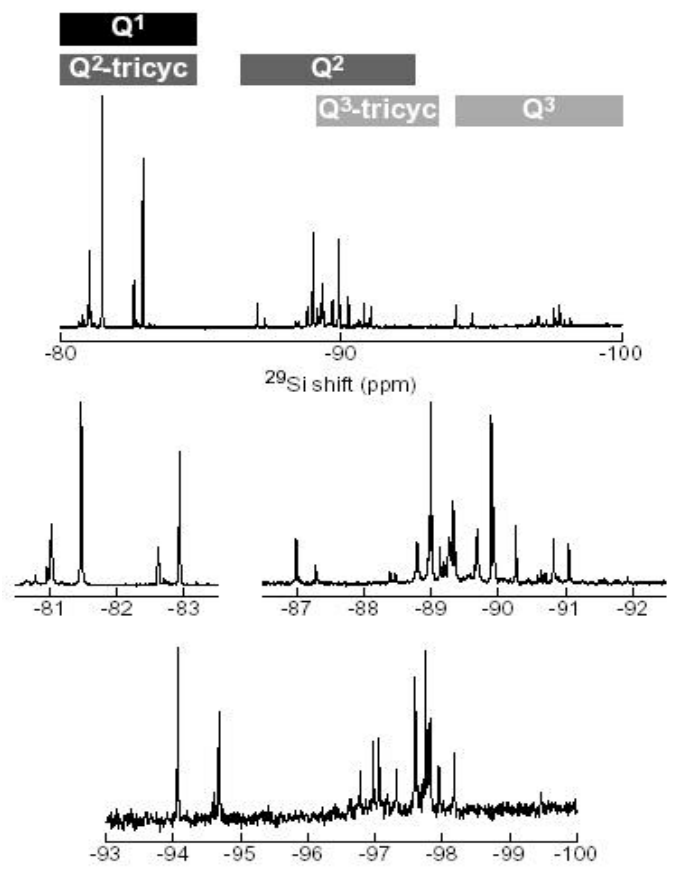

Figure 2. Natural abundance $(4.7 \%){ }^{29} \mathrm{Si} \mathrm{NMR} \mathrm{spectrum} \mathrm{of} 0.30$ molal $\mathrm{SiO}_{2}$ in 0.20 molal $\mathrm{NaOH}(\mathrm{aq})$, acquired at a ${ }^{29} \mathrm{Si}$ frequency of $99.30 \mathrm{MHz}$. The sample temperature was $15^{\circ} \mathrm{C}$. The $\mathrm{Q}^{0}$ region (>-80 ppm) and $Q^{4}$ region $(<-95 \mathrm{ppm})$ of the spectrum have been truncated; no $Q^{4}$ lines were observed. 
By analogy with tetravalent carbon, a tetravalent silicon atom under certain circumstances will not be superimposable on its mirror image. Any silicate species containing such a site therefore potentially has a structurally distinguishable isomeric counterpart with a different set of NMR lines. The rendering of such sites is problematic in a two-dimensional illustration, and representations such as those in Figure 1, which are common in the scientific literature on solution-state silicate structures, can conceal a multiplicity of distinct molecules that satisfy a given bonding network. Eight examples of silicate polymers containing chiral sites, which are highlighted, are depicted in Figure 3. In at least three of these polymers $(\mathrm{C}, \mathrm{D}$, and $\mathrm{E})$, one of the isomers formed by reflecting the chiral site appears not to be a realistic structure. For the other molecules, there is strong evidence indicating the existence of multiple isomeric forms. A manuscript describing the identification of these new species is in preparation.

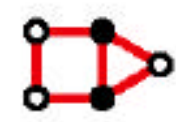

A

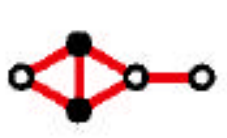

$\mathrm{E}$

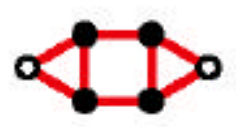

B

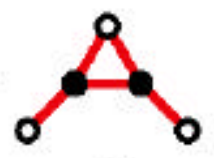

$\mathbf{F}$



C

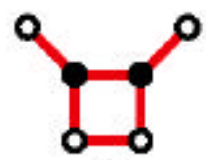

G

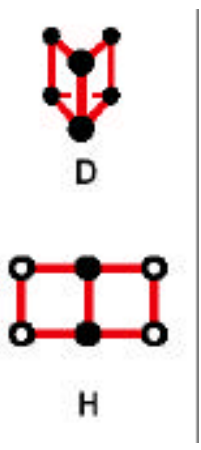

H

Figure 3. Silicate polymers containing chiral silicon atoms. The chiral sites are symbolized by filled circles. The top four polymers have previously been reported, while the bottom four polymers are proposed for the first time based on new two-dimensional NMR results.

\section{Summary of Silica Speciation Studies}

In summary, for the silica speciation studies, we have completed our aqueous thermodynamic model at $25^{\circ} \mathrm{C}$, developed a molecular model for polysilicates in solution, studied the kinetics of polmerization, and identified new enantomeric forms of the polysilicates. This effort has resulted in three manuscripts published or in review and one manuscript in preparation.

\section{Complexation Studies}

Once an accurate model of the aqueous silica reactions was established, the studies were focused on the radionuclide complexation reactions, specifically with $\mathrm{Sr}, \mathrm{Co}(\mathrm{II}), \mathrm{Eu}(\mathrm{III}) / \mathrm{Am}(\mathrm{III})$, and $\mathrm{U}(\mathrm{VI})$. These elements were selected because of their potential importance in the Hanford vadose zone and/or their relevance as analogs for other actinide oxidation states [i.e., Eu(III) as an analog for trivalent actinides and U(VI) as an analog for Pu(VI)]. Cobalt was selected for study even though the half-life of the dominant radioactive isotope ${ }^{60} \mathrm{Co}$ is only 5.26 years. Such a short half-life means that ${ }^{60} \mathrm{Co}$ probably will not represent a significant hazard to groundwater 
outside the immediate vicinity of a tank leak. Nevertheless, ${ }^{60} \mathrm{Co}$ is a significant contributor to the gamma logs used to assess the extent of radioactive material contamination in the vadose zone, so its movement and potential complexation with the dominant ligands present still must be assessed, at least in the immediate vicinity of a tank leak.

Studies were initiated at both Pacific Northwest National Laboratory (PNNL) and Florida State University (FSU). The studies at FSU focused on monomeric complexation and were investigated primarily by solvent extraction techniques. The studies at PNNL focused on polysilicate interactions and were conducted at higher base and dissolved silica concentrations. The results of these investigations are reported below.

\section{Strontium Studies}

Our current knowledge about the aqueous speciation and solubility of $\mathrm{Sr}$ in these basic silica solutions is almost completely absent. No definitive stability constants had yet been published for aqueous strontium silicate species, and only a very limited number of strontium silicate solids (i.e., $\mathrm{SrSiO}_{3}, \mathrm{Sr}_{2} \mathrm{SiO}_{4}, \mathrm{Na}_{4} \mathrm{SrSi}_{3} \mathrm{O}_{9}, \mathrm{SrSiO}_{3}, \ldots$ ) had been identified and characterized . With these factors in mind, the purposes of this study were 1) to determine if highly basic silica-containing solutions result in the formation of soluble strontium-silicate complexes or result in the precipitation of insoluble strontium silicate solids, and 2) to identify, if possible, the phases or solution species that form and their solubility products or aqueous complexation constants. To achieve these objectives, we conducted solubility studies of strontium silicate solutions over a range of dissolved silica, strontium, and hydroxide concentrations extending to long equilibration times (286 days). The solid phases formed in the system were analyzed by a variety of techniques including total chemical analysis, $\mathrm{x}$-ray diffraction (XRD), scanning electron microscopy (SEM), and thermogravimetric analysis (TGA).

The results showed that amorphous strontium silicate precipitates can form from aqueous solution beginning at approximately $\mathrm{pH} 10$ and become quasi-crystalline at higher $\mathrm{pH}$ (11.5 to 12). The quasi-crystalline precipitates have a chemical formula of $\operatorname{Sr}_{5} \mathrm{Si}_{6} \mathrm{O}_{16}(\mathrm{OH})_{2} \cdot 5 \mathrm{H}_{2} \mathrm{O}$, a structure similar to tobermorite, and a solubility product of $\log \mathrm{K}=-38.0 \pm 0.7$ for the overall reaction, $5 \mathrm{H}_{2} \mathrm{O}+\mathrm{Sr}_{5} \mathrm{Si}_{6} \mathrm{O}_{16}(\mathrm{OH})_{2} 5 \mathrm{H}_{2} \mathrm{O}=5 \mathrm{Sr}^{2+}+6 \mathrm{H}_{3} \mathrm{SiO}_{4}{ }^{-}+4 \mathrm{OH}^{-}$. The $\mathrm{Sr}_{5} \mathrm{Si}_{6} \mathrm{O}_{16}(\mathrm{OH})_{2} \cdot 5 \mathrm{H}_{2} \mathrm{O}$ phase has not been previously reported. Scanning electron microscopy analysis of the alcoholwashed precipitates showed a fine granular structure similar to calcium silicate hydrates. Deionized water-washing of the precipitates resulted in dissolution and growth of surface phases with the classical "sheaf of wheat" nucleation structure previously identified only for calcium silicate hydrates. No evidence for $\mathrm{Sr}^{2+}$ complexation with polysilicate species was observed. An association constant for the monomeric species $\mathrm{SrH}_{2} \mathrm{SiO}_{4}(\mathrm{aq})$ of $\log \mathrm{K}=2.86$ was estimated, but such a species never accounted for more than $50 \%$ of the total dissolved Sr concentration. This conclusion was extensively tested in solutions of variable $\mathrm{Si} / \mathrm{Sr}$ ratio, $\mathrm{pH}$, ionic strength, and 
other characteristics. All of these data indicate that the $\mathrm{Sr}$ (II)-anionic silica interactions are not as strong as the corresponding solid phase formation reactions. Therefore, it is unlikely that dissolved silica species can be a significant transport vector for $\mathrm{Sr}$ in these basic, high-silica solutions. These studies have been completed and the results submitted and accepted for publication.

\section{Solvent Extraction Studies of Monomeric Silica Complexation}

The interactions of $\mathrm{UO}_{2}^{2+}, \mathrm{Eu}^{3+}, \mathrm{Am}^{3+}, \mathrm{Co}^{2+}$, and $\mathrm{Ni}^{2+}$ with monosilicic acid were studied by solvent extraction methods at $\mathrm{FSU}$. $\mathrm{Ni}^{2+}$ was included with the other metal ions principally to provide a check on the results for $\mathrm{Co}^{2+}$ as described below. The final results are reported in Table 1.

Table 1. Stability Constants for Metal - o-Siliciate Complexes

\begin{tabular}{|l|c|l|l|}
\hline $\begin{array}{c}\text { Metal } \\
\text { Ion }\end{array}$ & \multicolumn{1}{c|}{$\log \hat{\mathbf{a}}_{\mathbf{1}}$} & \multicolumn{1}{c|}{$\log \hat{\mathbf{a}}_{\mathbf{2}}$} & $\mathbf{I}, \mathbf{M}$ \\
\hline $\mathrm{UO}_{2}{ }^{2+}$ & $6.79 \pm 0.25$ & $12.85 \pm 0.28$ & 0.20 \\
\hline $\mathrm{Am}^{3+}$ & $7.46 \pm 0.22$ & & 0.20 \\
\hline $\mathrm{Eu}^{3+}$ & $7.04 \pm 0.15$ & 11.7 & 0.20 \\
\hline $\mathrm{Co}^{2+}$ & $4.85 \pm 0.25$ & & 0.20 \\
\hline $\mathrm{Ni}^{2+}$ & $5.41 \pm 0.23$ & & 0.20 \\
\hline
\end{tabular}

The stability constants for $\mathrm{UO}_{2}(\mathrm{II}), \mathrm{Eu}(\mathrm{III})$, and $\mathrm{Am}$ (III) complexes agree fairly well with the corresponding literature values even though the ortho-silicate concentration was determined using the new model developed in this project. The value for Am(III) is also greater than for $\mathrm{Eu}(\mathrm{III})$ in a consistent fashion for what is expected from carbonate and hydroxide complexes. The value for $\mathrm{Co}(\mathrm{II})$ is also slightly less than the value for $\mathrm{Ni}(\mathrm{II})$ consistent with complexation strength of these two cations for other ligands. The results for $\mathrm{Co}$ (II) are particularly interesting as even the stability constant for the monosilicic acid complex $\left(\mathrm{CoH}_{3} \mathrm{SiO}_{4}{ }^{+}\right)$has an equilibrium constant approximately $1.5 \mathrm{log}$ units greater than the corresponding carbonate complex. Thermodynamic calculations using these data and our new data on silicate species formation, along with the hydrolysis constants for $\mathrm{Co}(\mathrm{II})$, indicate that the $\mathrm{Co}$ (II) silicate complex will predominate over all other solution species from $\mathrm{pH} 8$ to approximately 11.5 and to high carbonate concentration [saturation with respect to $\mathrm{CoCO}_{3}(\mathrm{c})$ ]. Therefore, even in the absence of polysilicate complexation, $\mathrm{Co}$ (II) transport will be significantly facilitated by the presence of dissolved silica over the typical range of $\mathrm{pH}$ values found in the vadose zone. A manuscript on these results is being prepared for publication. 
These results for the monomeric complexes also are needed to help unambiguously interpret experiments at higher dissolved silica concentration where a variety of polysilicate-metal complexes can be present.

\section{Anion and $\mathrm{Cs}^{+}$interactions}

In addition to the metal silicate complexation reactions that have been studied, selected experiments were conducted with anions $\left(\mathrm{SO}_{4}{ }^{2-}, \mathrm{F}^{-}\right.$, and $\left.\mathrm{PO}_{4}{ }^{3-}\right)$ to determine if any significant silicate-anion interactions occurred in solution. Such interactions have been clearly identified in more acidic solutions, but no clear information existed under basic conditions. Therefore, screening-level studies were conducted. The studies provided measurements of the NMR spectra of identical solutions in which a small fraction of the background electrolyte, $\mathrm{NaNO}_{3}$, was replaced by the corresponding anionic salt (e.g., $\mathrm{NaF}, \mathrm{Na}_{2} \mathrm{SO}_{4}, \ldots$ ). In all cases examined, the NMR spectra were identical, indicating a lack of strong complexation effects of these anions at high $\mathrm{pH}$.

Interestingly, when the $\mathrm{NaNO}_{3}$ electrolyte was replaced by $\mathrm{CsNO}_{3}$, new previously unidentified peaks appeared at ${ }^{29} \mathrm{Si}$ chemical shifts values typical of polysilicate complexes. We are preparing different solutions at variable $\mathrm{CsNO}_{3}$ concentration and silicate concentration in an attempt to identify the new species that formed. At this time, our best estimate is that they represent previously unidentified Cs-polysilicate species. Although such species represent only a small fraction of the total Cs in solution (the vast majority is free $\mathrm{Cs}^{+}$), identification of such species and determining the range of their stability may help shed light onto more complex and important Cs-silicate interactions. Such Cs-silicate interactions, specifically Cs uptake at frayed edge sites on aluminosilicates, are believed to be the dominant mechanism of Cs attenuation in the Hanford vadose zone.

\section{Development of Reactive Transport Models}

To help ensure that the thermodynamic data gathered as part of this study were applied to actual vadose zone issues at Hanford and other DOE sites, we collaborated with several investigators on the Hanford Vadose Zone Science and Technology (HVZS\&T) program. As part of this collaboration, we have supplied the necessary computer code to implement the Pitzer thermodynamic model in the subsurface reactive transport models being used to model reactive chemical transport in the vadose zone. The most recent thermodynamic database, developed as part of this and other projects, was also supplied and updated during this study. 


\section{Information Access}

\section{Publications and Presentations}

Felmy AR, HM Cho, JR Rustad, DA Dixon, and GR Choppin. 2000. The Aqueous

Thermodynamics and Complexation Reactions of Anionic Silica Species to High Concentration. EMSP Vadose Zone Workshop Presentation, November 28, Richland, WA.

Felmy AR, HM Cho, JR Rustad, and MJ Mason. 2001. An Aqueous Thermodynamic Model for Polymerized Silica Species to High Ionic Strength. J. of Solution Chemistry 30:509-525.

Felmy AR, MJ Mason, PL Gassman, and DE McCready. The Formation of Strontium Silicates at Low Temperature and the Solubility Product of Tobermorite Like $\mathrm{Sr}_{5} \mathrm{Si}_{6} \mathrm{O}_{16}(\mathrm{OH})_{2} \cdot 5 \mathrm{H}_{2} \mathrm{O}$. American Mineralogist. Accepted.

Felmy AR, HM Cho, GR Choppin, DA Dixon, JR Rustad, and Z Wang. 2001. The Aqueous Thermodynamics and Complexation Reactions of Anionic Silica Species to High Concentration. EMSP Vadose Zone Workshop Presentation, November 4-6, Richland, WA.

Krejzler J and GR Choppin. Factors Affecting Free o-Silicate Concentration in Aqueous Solution. Talanta. In review.

Krejzler J and GR Choppin. 2001. Complexation of Metal Cations by o-silicates. Presented at the $222^{\text {nd }}$ ACS National Meeting, August 26-30, Chicago, IL.

Lichtner PC and AR Felmy. Estimation of Hanford SX Tank Waste Compositions from Historically Derived Inventories. Computers \& Geosciences. Special issue on Reactive Transport Modeling in the Geosciences. Accepted.

Rustad JR, AR Felmy, KM Rosso, and EJ Bylaska. Ab initio investigation of the structures of $\mathrm{NaOH}$ hydrates and their $\mathrm{Na}^{+}$and $\mathrm{OH}^{-}$coordination polyhedra. American Mineralogist. In review.

Wang Z, X Xia, MJ Mason, and AR Felmy. 2001. Investigations of Cm(III) Speciation in Strongly Basic Solutions by Time Resolved Laser Fluorescence Spectroscopy. Presented at the $222^{\text {nd }}$ ACS National Meeting, August 26-30, Chicago, IL. 


\section{Other Contributions}

In addition to the previously described scientific contributions, the principal investigators on this project also worked to enhance the overall success of the EMSP program. Specifically,

- Andrew Felmy (PNNL) was a co-organizer of the Accomplishment of the Environmental Management Sciences Program (EMSP) Symposium at the $222^{\text {nd }}$ ACS National Meeting held in Chicago, Illinois, on August 26-30, 2001. The symposium consisted of five different sessions covering the areas of subsurface science, solution and tank chemistry, radionuclide and contaminant separation methods, analytical and sensing techniques, and waste form treatment and development. There were 65 oral or poster presentations in the symposium.

- Greg Choppin (FSU) serves as a member of the EMSP Advisory Committee and of the NAS/NRC Board of Radioactive Waste Management.

In addition to other technical presentations, the principal investigators on this project gave two presentations at EMSP/HVZGWP coordination meetings held in Richland, Washington. 